
\title{
28 Research Square \\ The Influence of Friction Blocks Connection Configuration on High-speed Railway Brake Systems Performance
}

Jiabao Yin

Southwest Jiaotong University

Yuanke Wu

Southwest Jiaotong University

Chun Lu

Southwest Jiaotong University

Wei Chen

Southwest Jiaotong University

Jiliang Mo ( $\nabla$ jlmo@swjtu.cn )

Southwest Jiaotong University https://orcid.org/0000-0001-6602-154X

\section{Zhongrong Zhou}

Southwest Jiaotong University

\section{Research Article}

Keywords: Brake, Friction block, Connect configuration, Braking performance

Posted Date: February 8th, 2021

DOI: https://doi.org/10.21203/rs.3.rs-171197/v1

License: () (1) This work is licensed under a Creative Commons Attribution 4.0 International License.

Read Full License

Version of Record: A version of this preprint was published at Tribology Letters on August 23rd, 2021. See the published version at https://doi.org/10.1007/s11249-021-01497-9. 


\section{Abstract}

The influence of friction blocks connection configuration on the interfacial tribology behavior and FIVN (friction-induced vibration and noise) of high-speed railway braking system is systematically investigated with a scaled brake test bench. The potential relationship among interface contact status, friction, wear, pressure distribution, heat distribution and vibration noise of the system is studied under dragging test condition. The results indicate that the connection configuration of the friction blocks has a significant impact on systematic interfacial tribology behavior, heat distribution and vibration noise. A floating connection mode can suppress the vibration noise of brake system. The interfacial heat distribution and systematic vibration noise are quite relevant with the contact status, interfacial wear and pressure distribution. The increase of interfacial wear will lead to an expansion of pressure concentration area and an aggravation of vibration noise. The result of this research is helpful for a further design optimization and noise reduction of railway brake system.

\section{Full Text}

This preprint is available for download as a PDF.

\section{Figures}

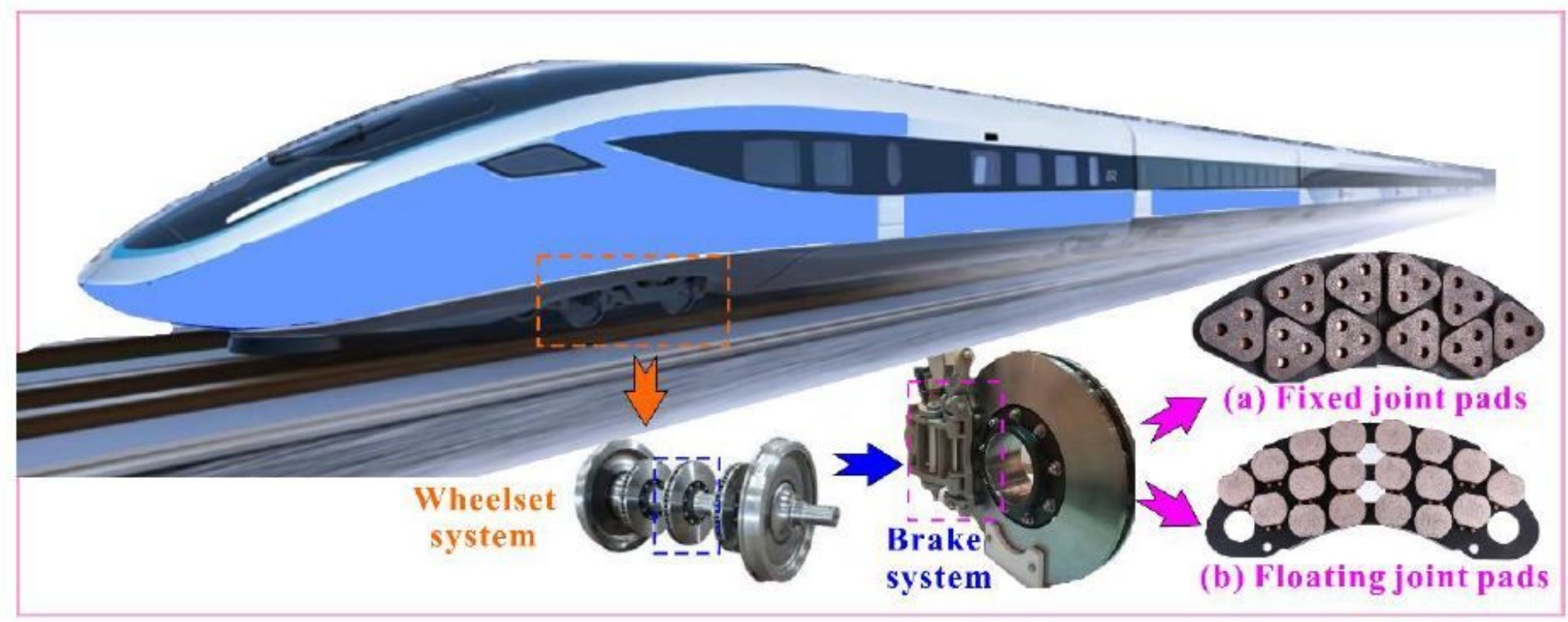

\section{Figure 1}

Brake pads of two connection modes and related systems, (a) fixed joint pads for China Railcar $\mathrm{CRH} 5 \mathrm{~A} / 5 \mathrm{G} / 5 \mathrm{E}$, (b) floating joint pads for China Railcar CRH380B/BG 


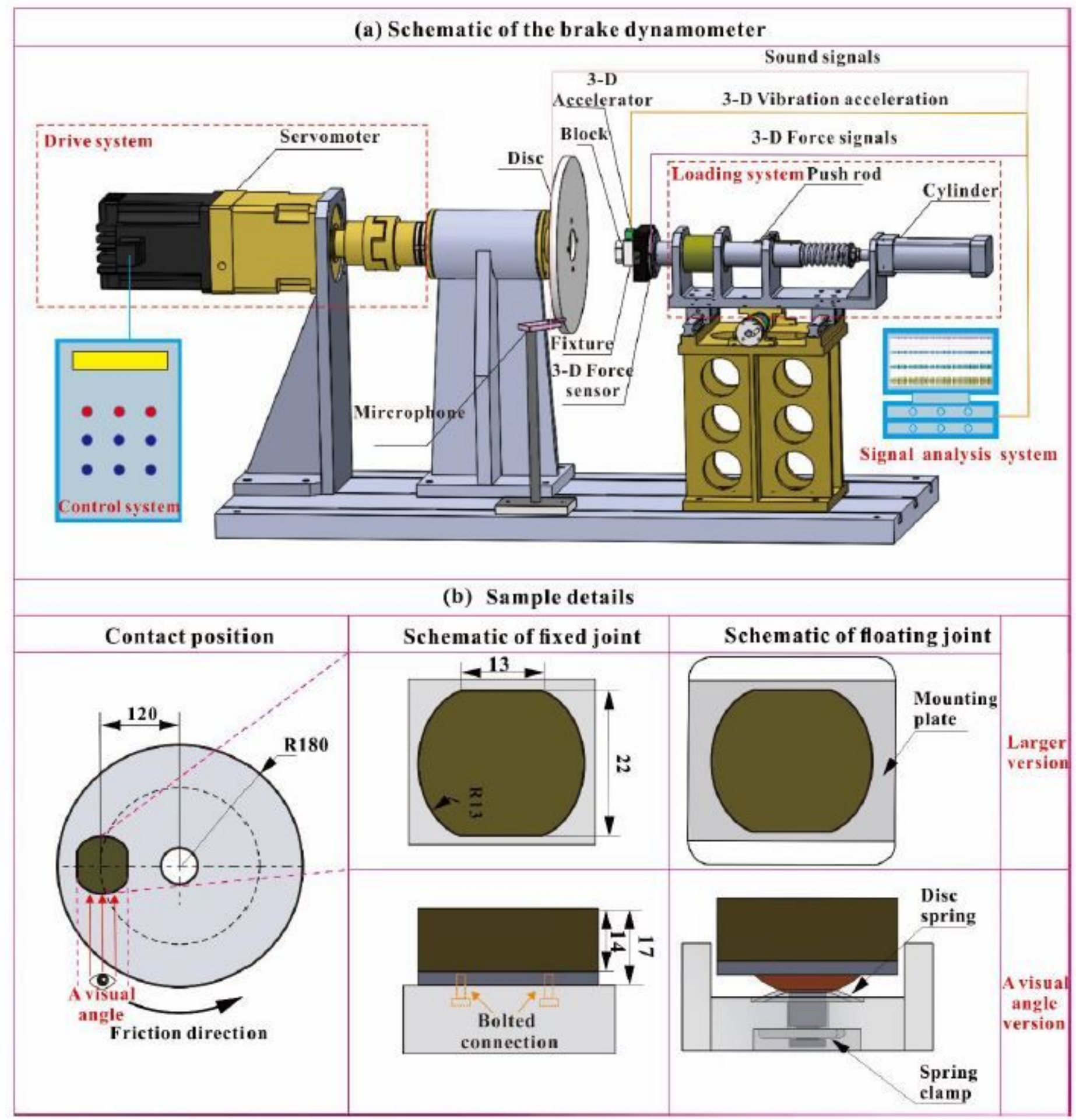

Figure 2

Schematic of the brake dynamometer and samples 


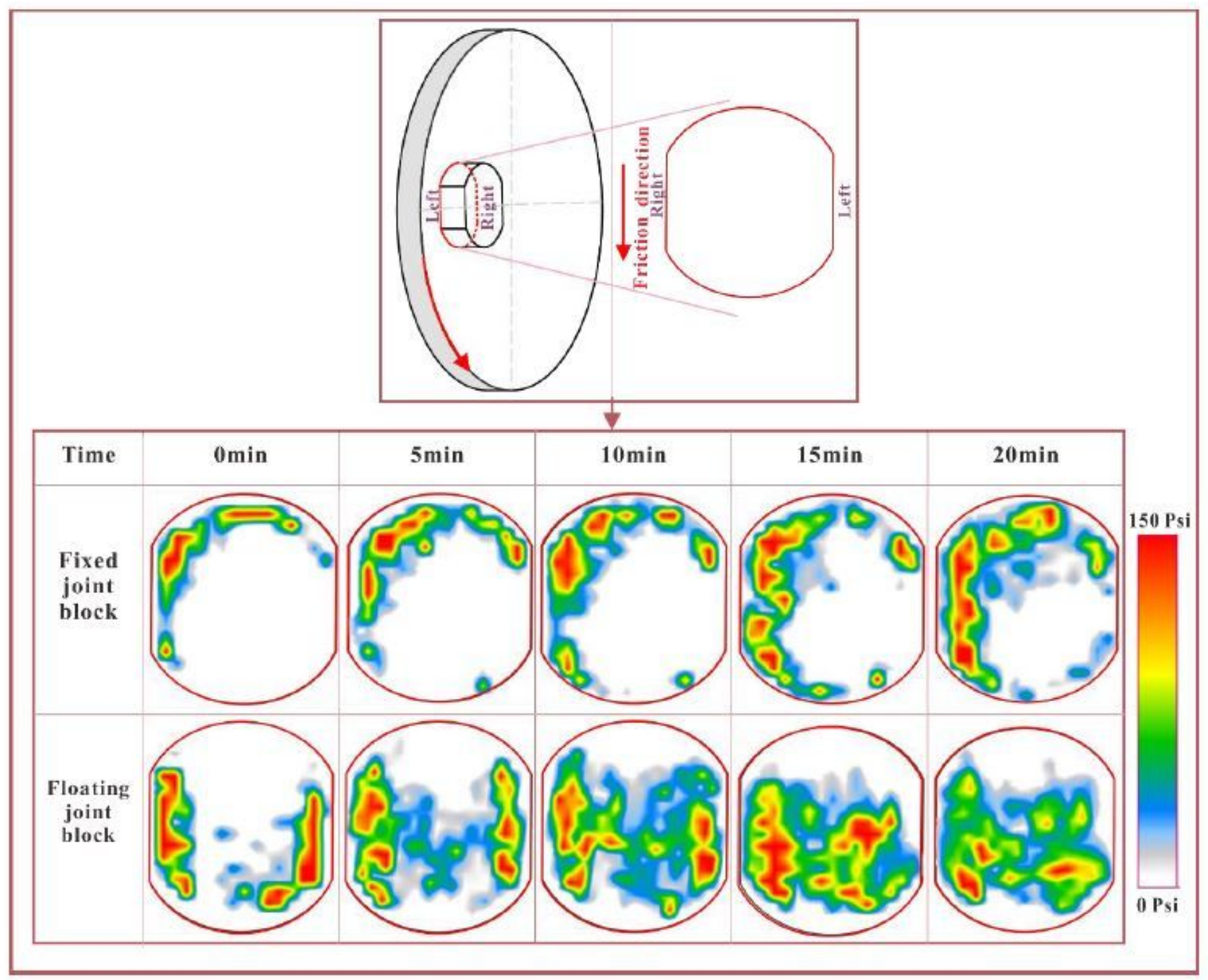

Figure 3

Time domain evolution of the distribution of contact area for two interfaces with different connection modes (1 Psi $\approx 6.89 \times 10-3 \mathrm{MPa}$ ) 


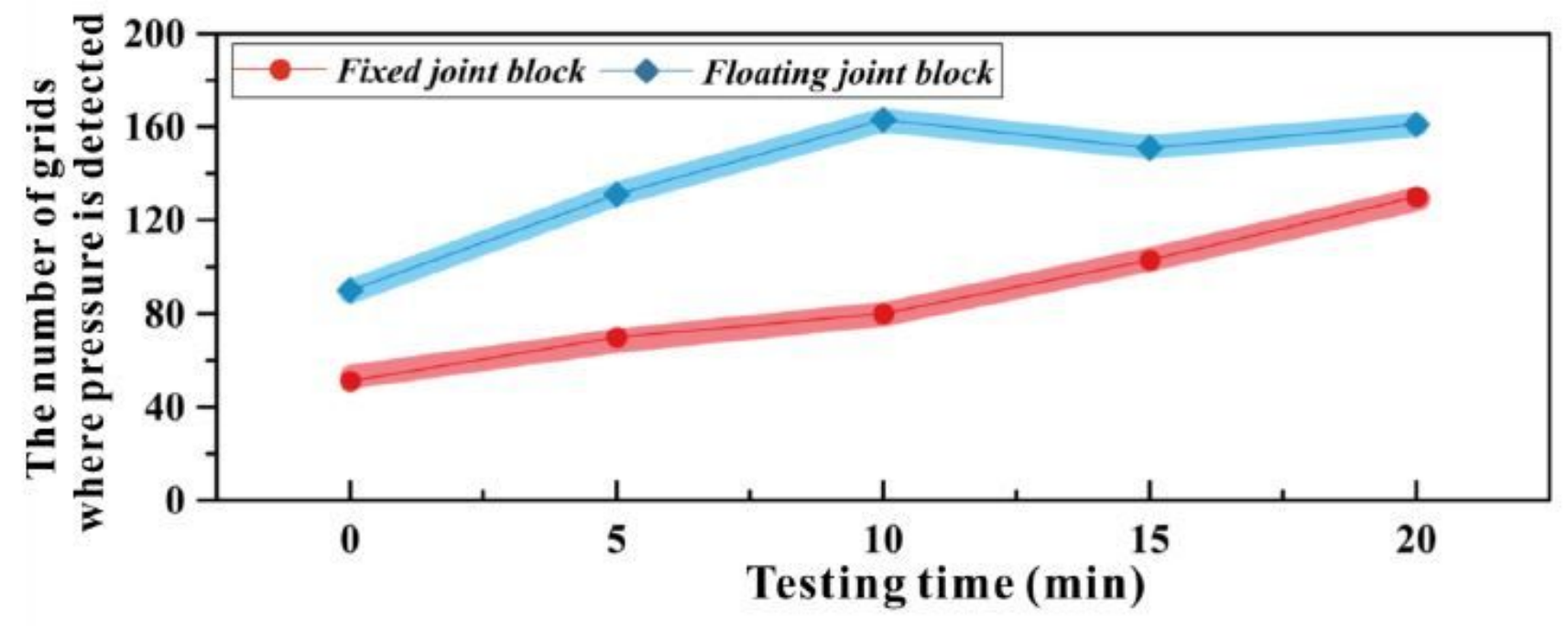

Figure 4

Time domain evolution of contact area for two interfaces with different connection modes (the size equals to approximately $2.52 \mathrm{~mm} 2$ per grid) 


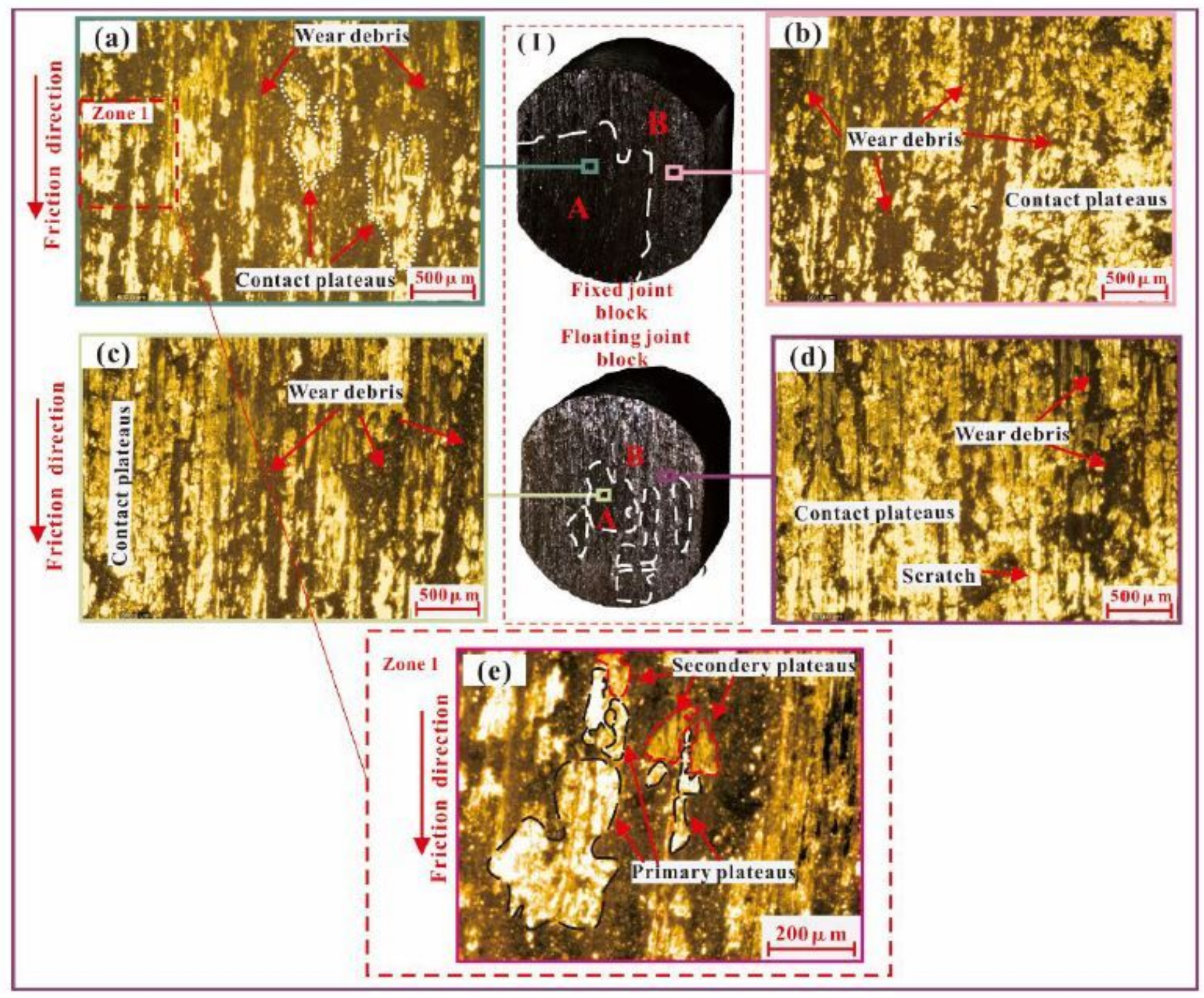

Figure 5

Light micrographs of region A and B on the two friction block surfaces after the experiment 


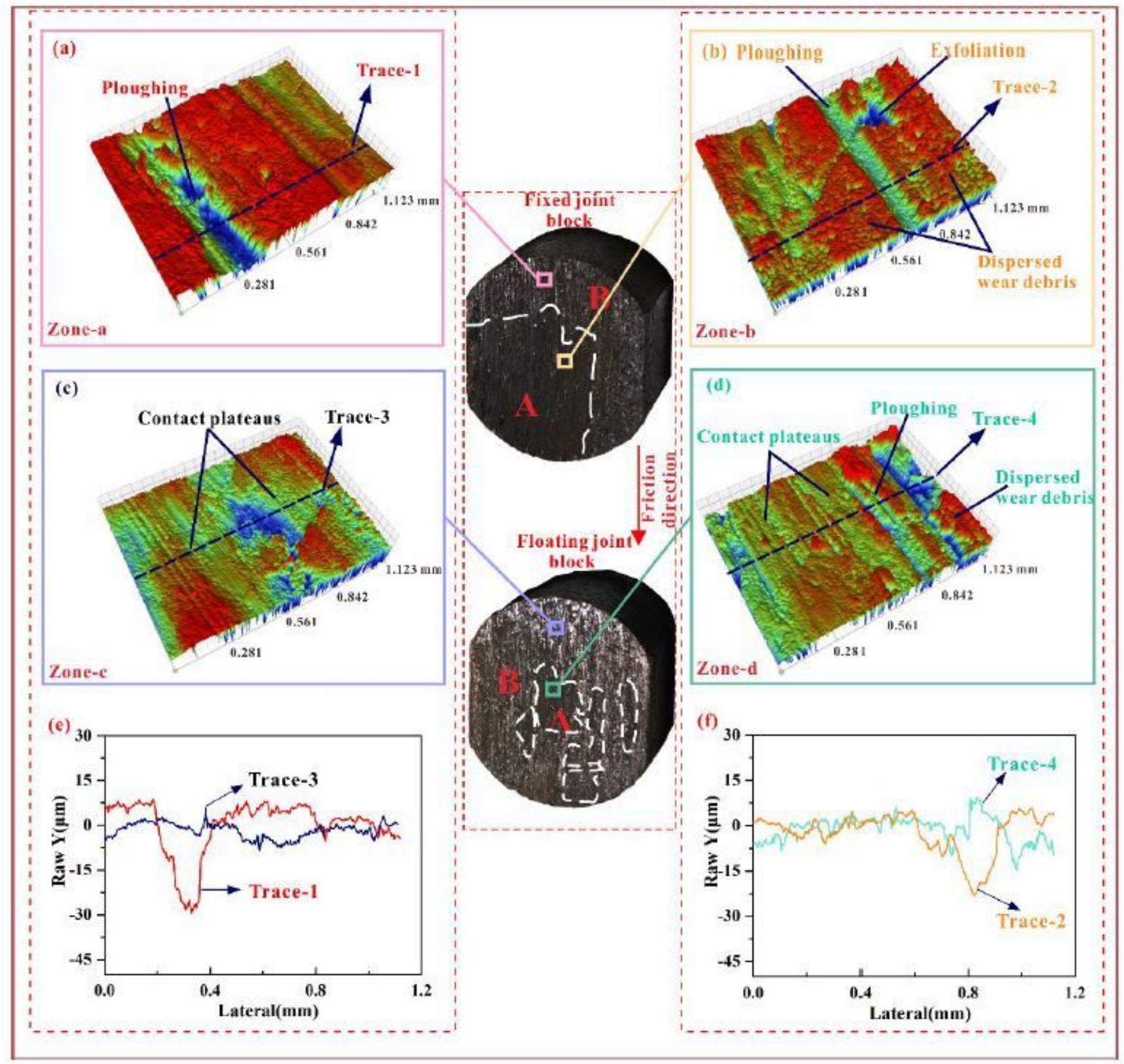

Figure 6

3-D topography and 2-D profile around zone-a, zone-b, zone-c, and zone-d of the worn surface of both friction blocks 

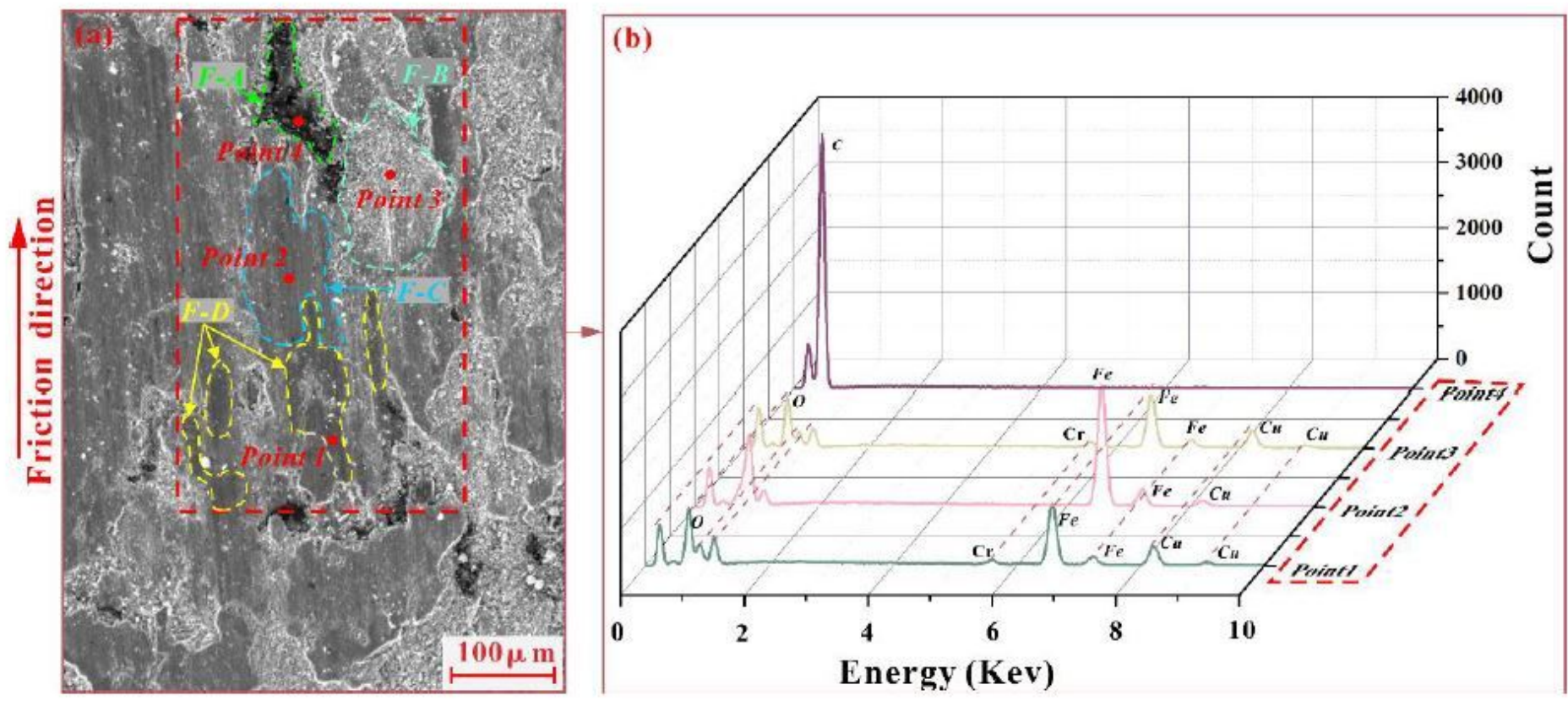

Figure 7

SEM and EDX analysis of different structures in the region $A$ of the fixed joint block

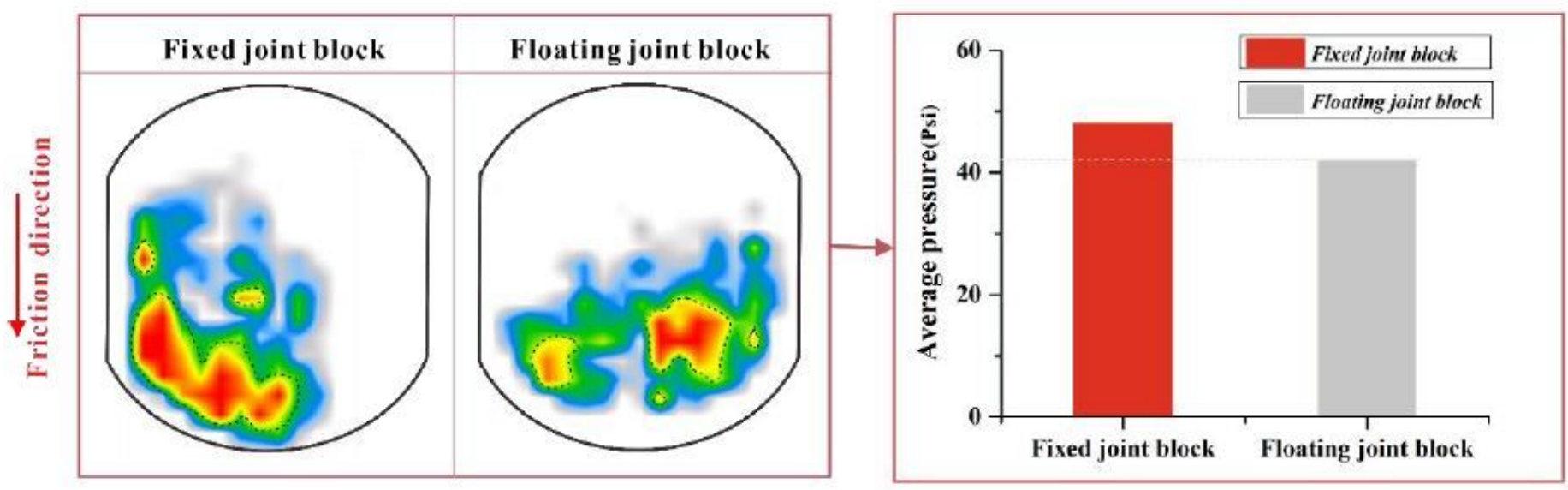

Figure 8

Comparison of pressure distribution and average pressure on two interfaces ( $1 \mathrm{Psi} \approx 6.89 \times 10-3 \mathrm{MPa})$ 


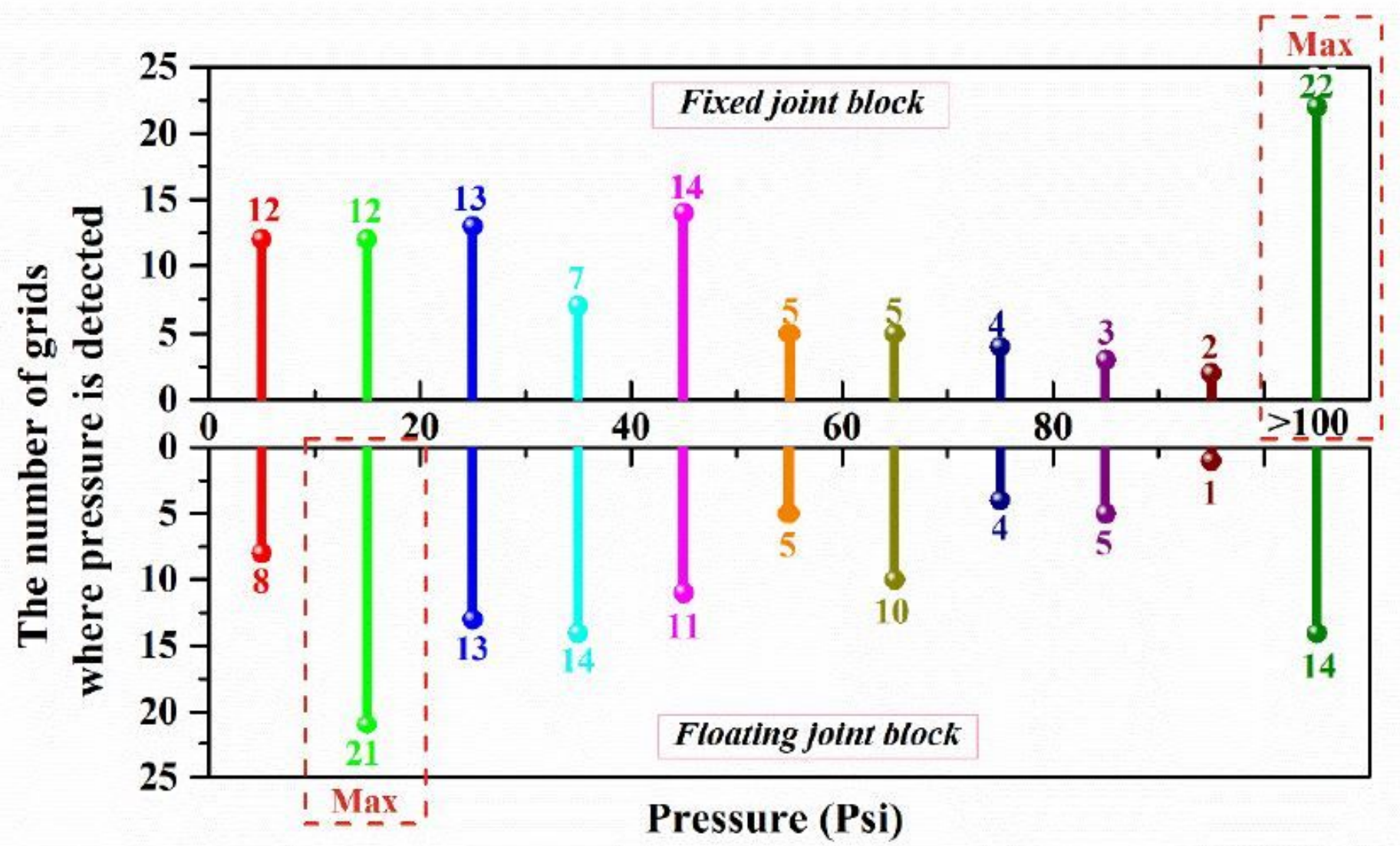

Figure 9

Comparison of contact areas corresponding to different pressure value on two interfaces (the size of each sensing grid equals approximately $2.52 \mathrm{~mm} 2$ ) 


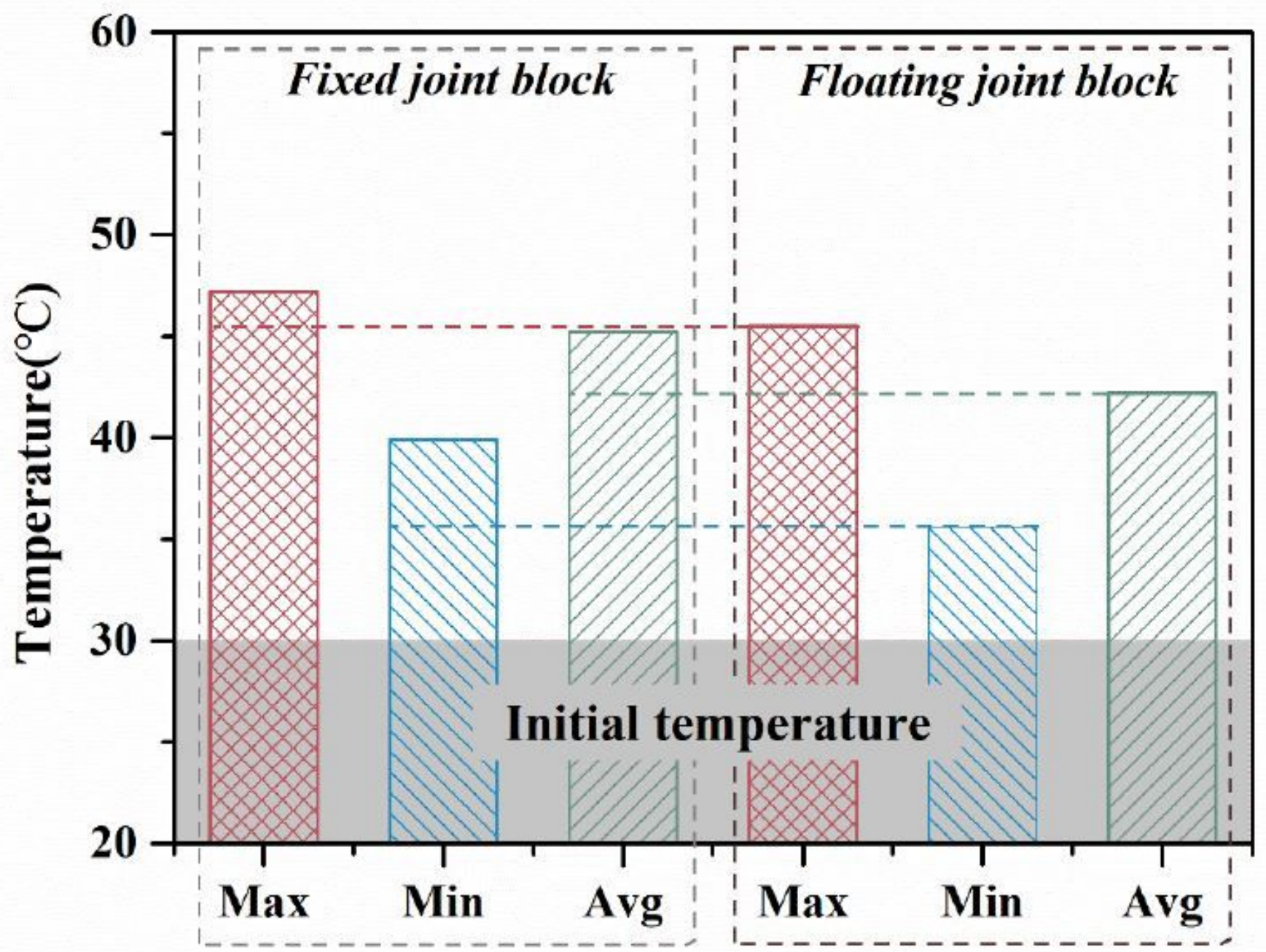

Figure 10

Comparison of surface temperature difference between two friction blocks

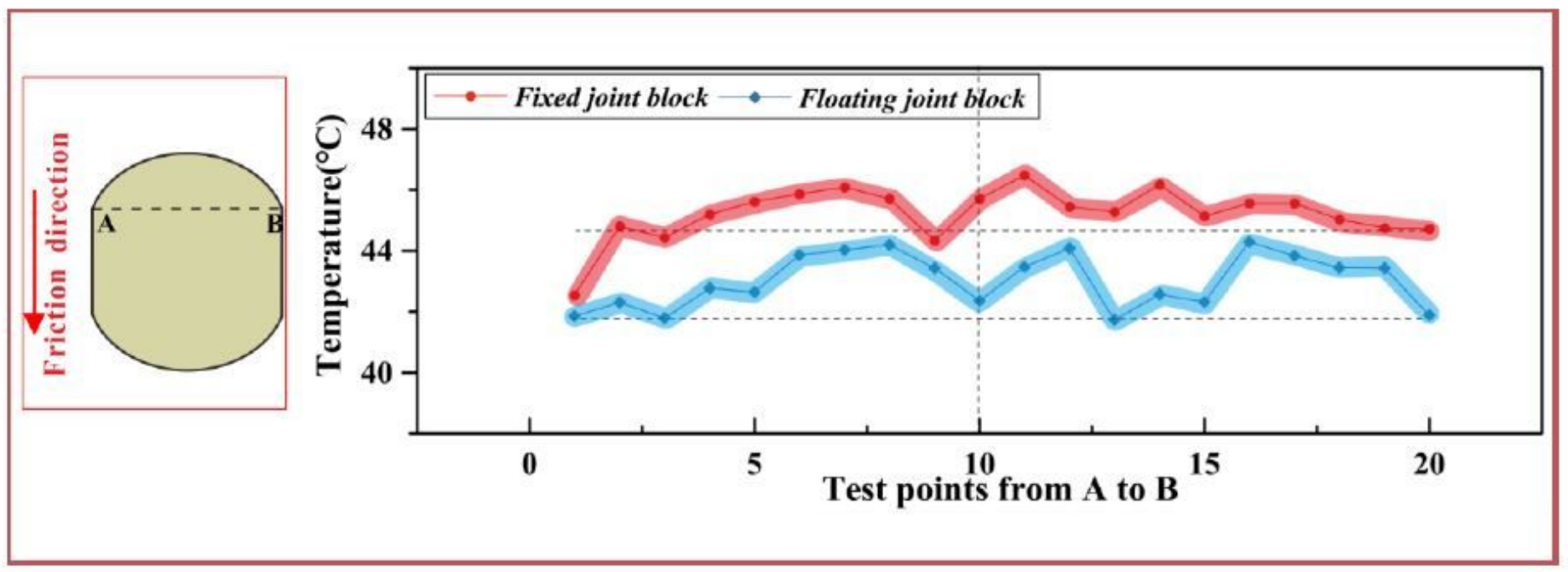


Figure 11

Comparison of heat distribution uniformity on the interface between two friction blocks

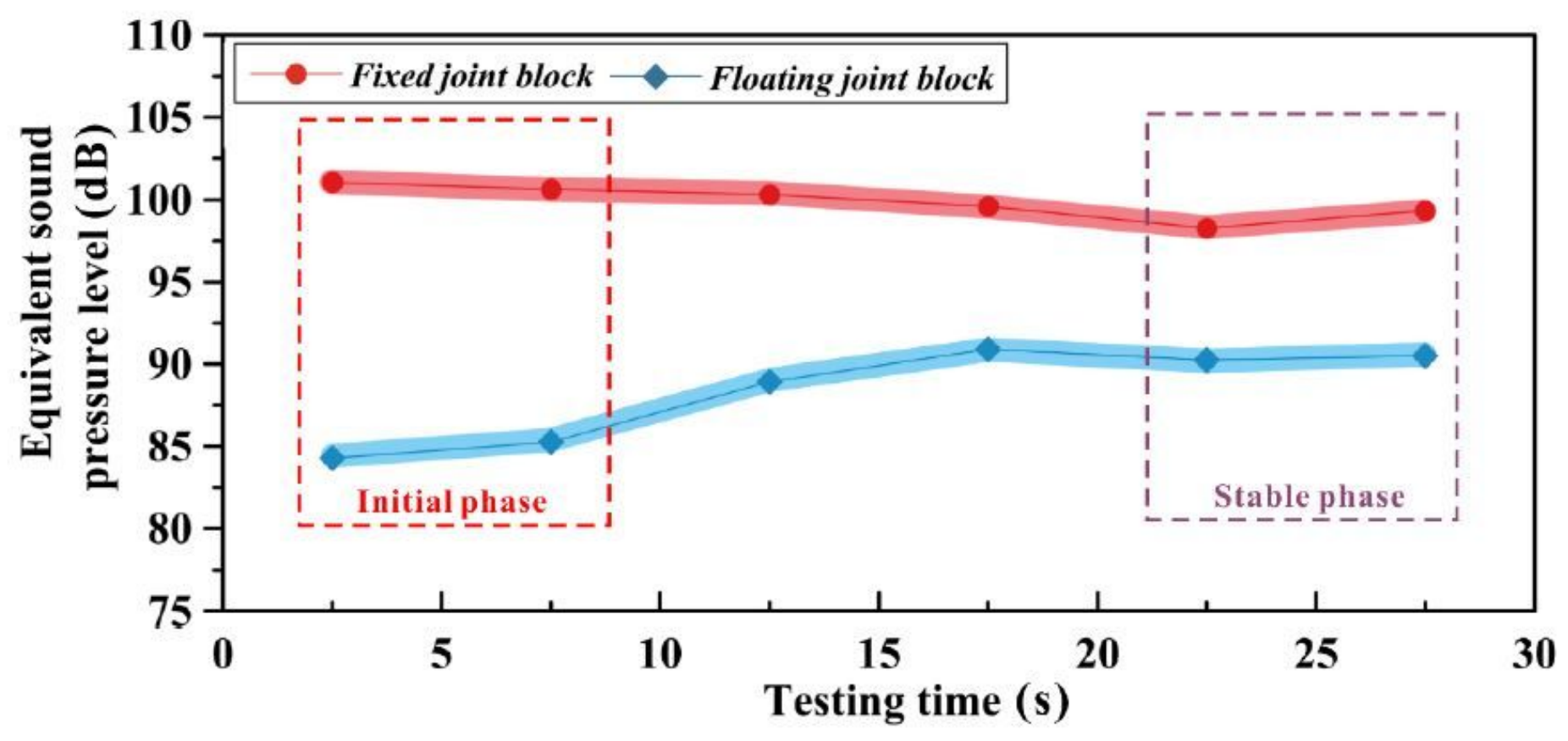

Figure 12

Equivalent sound pressure level analysis of two braking systems 

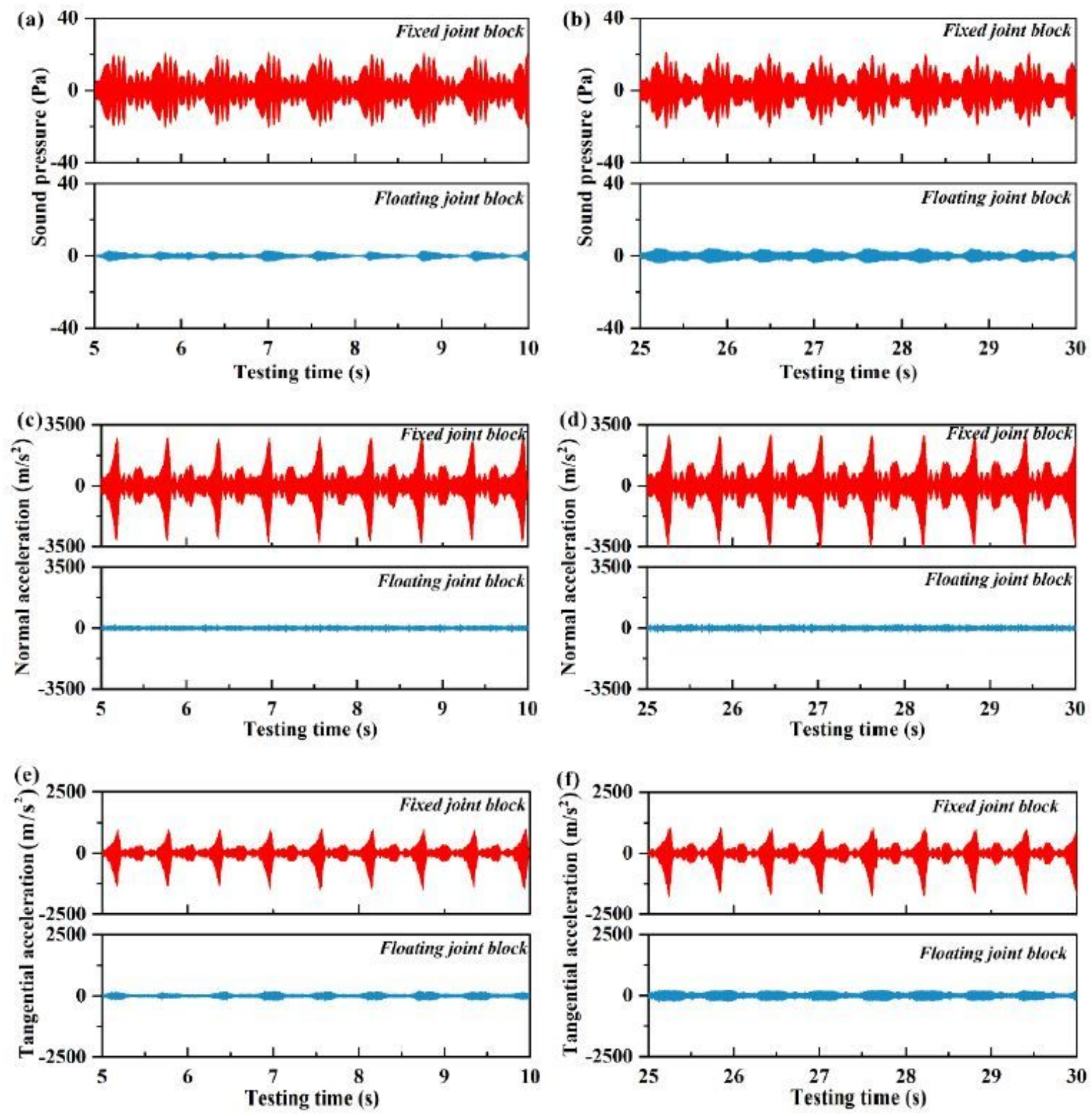

\section{Figure 13}

Two-stage vibration noise and vibration acceleration signals for the system of fixed and floating connection modes 


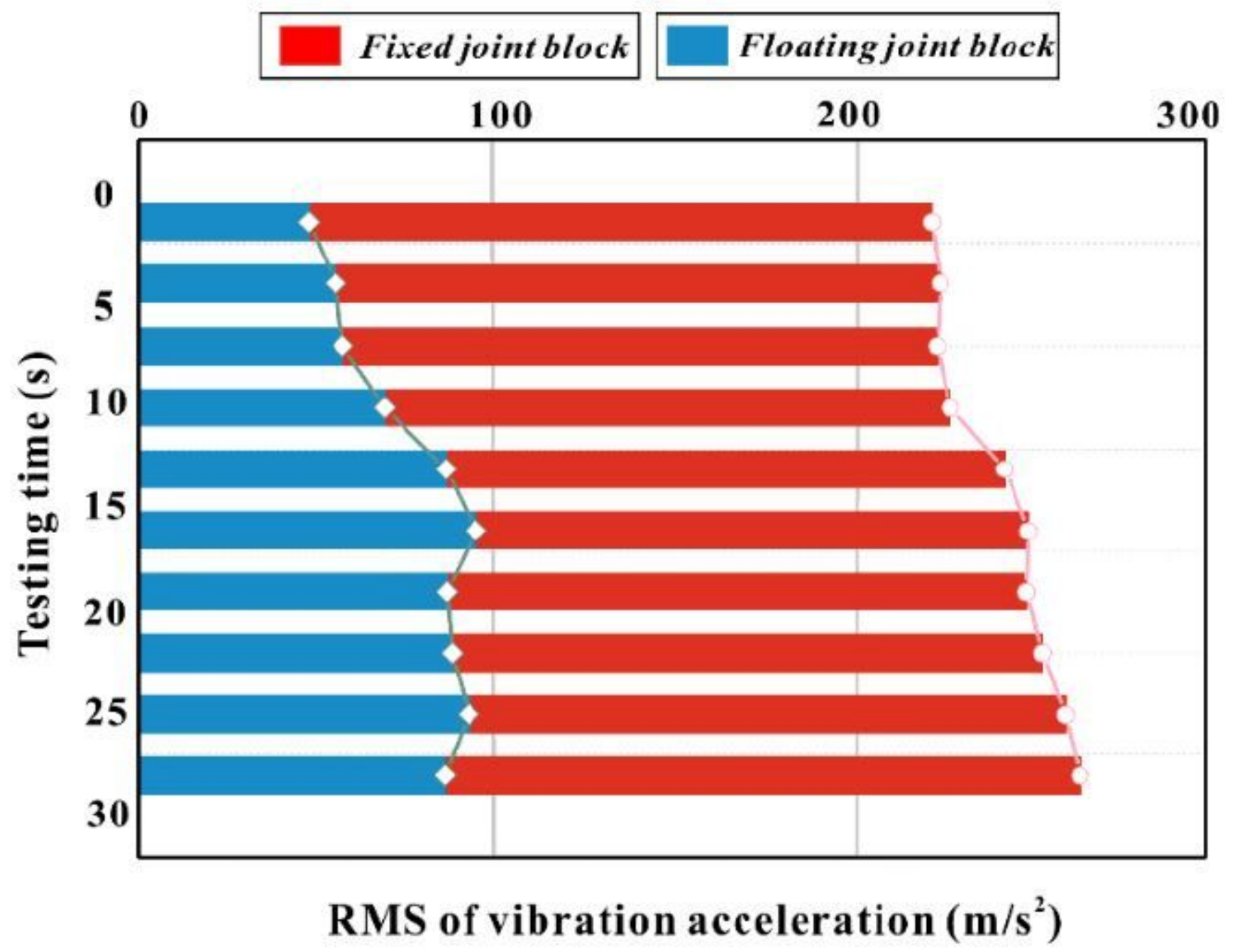

Figure 14

Comparison of RMS of tangential vibration acceleration between two friction systems 
(a)

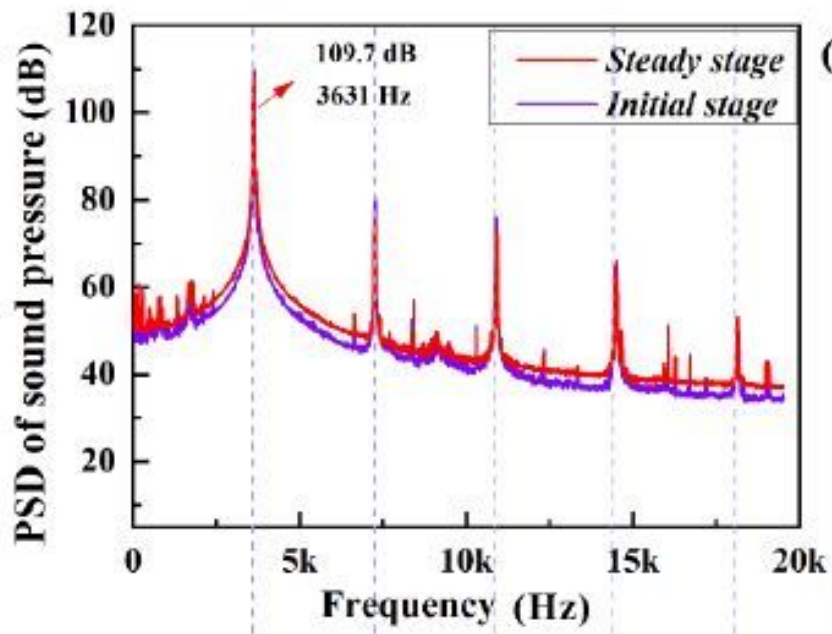

(c)

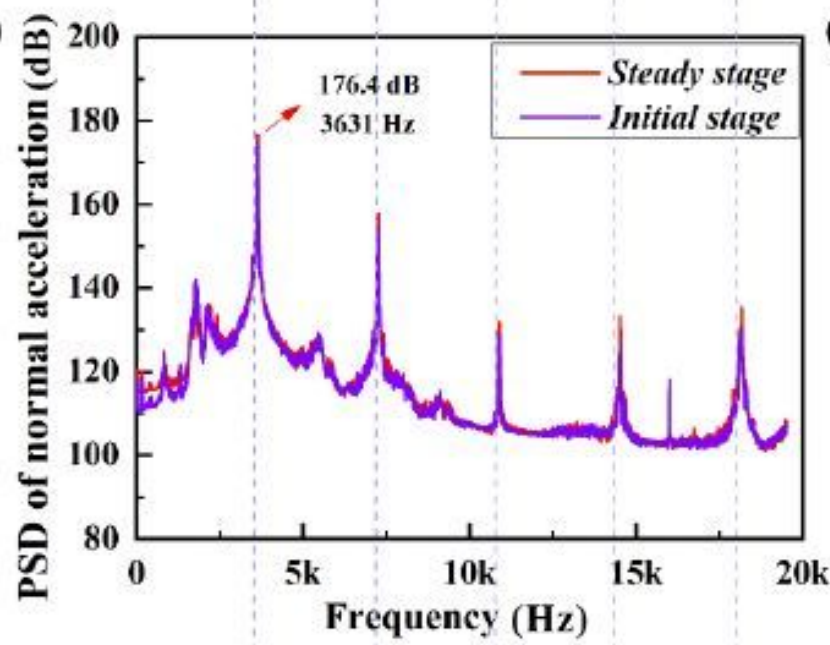

(e)

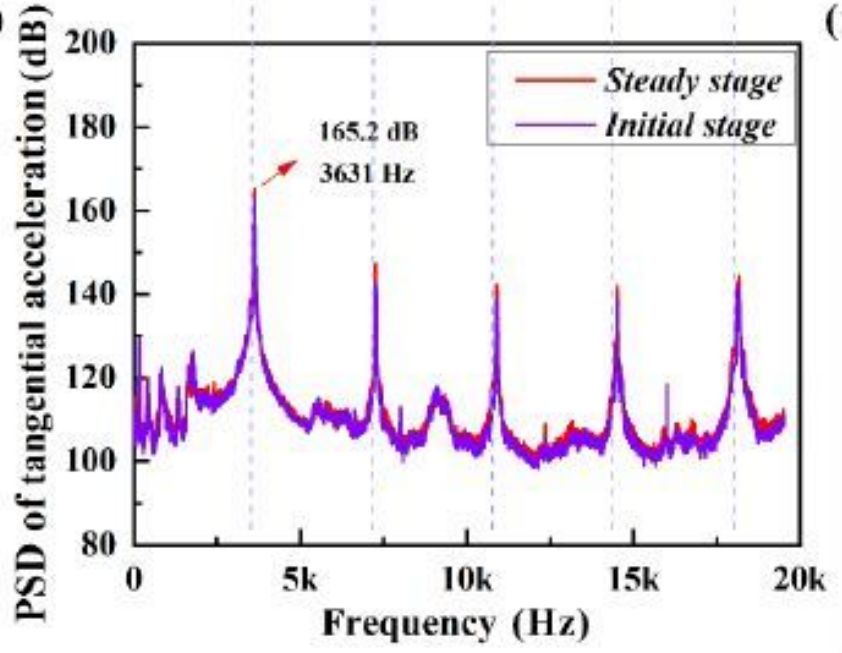

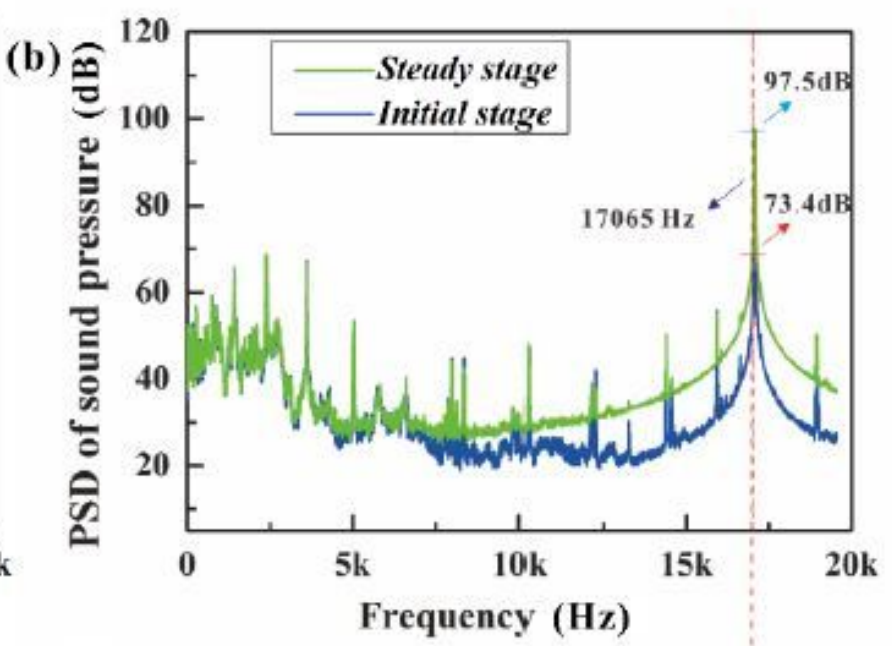

(d)

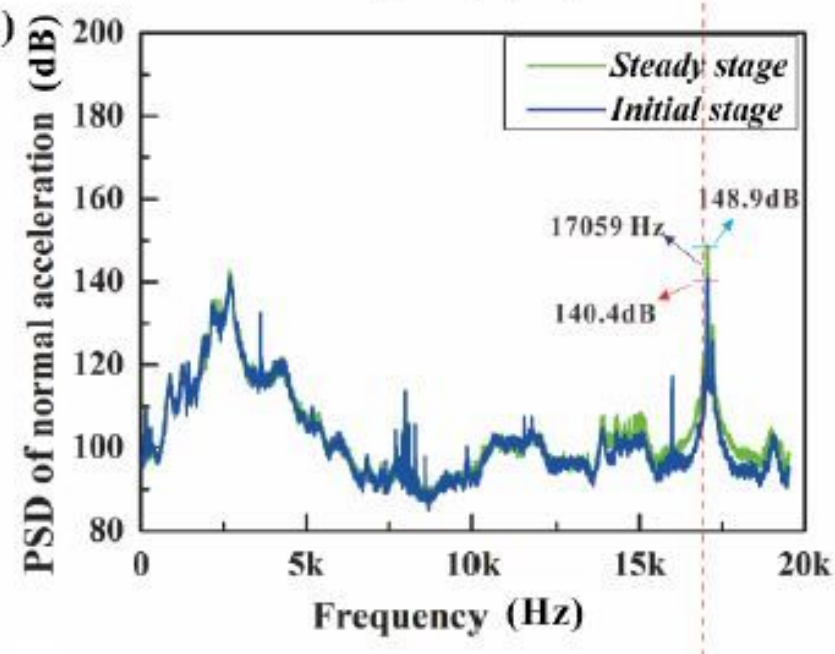

(f)

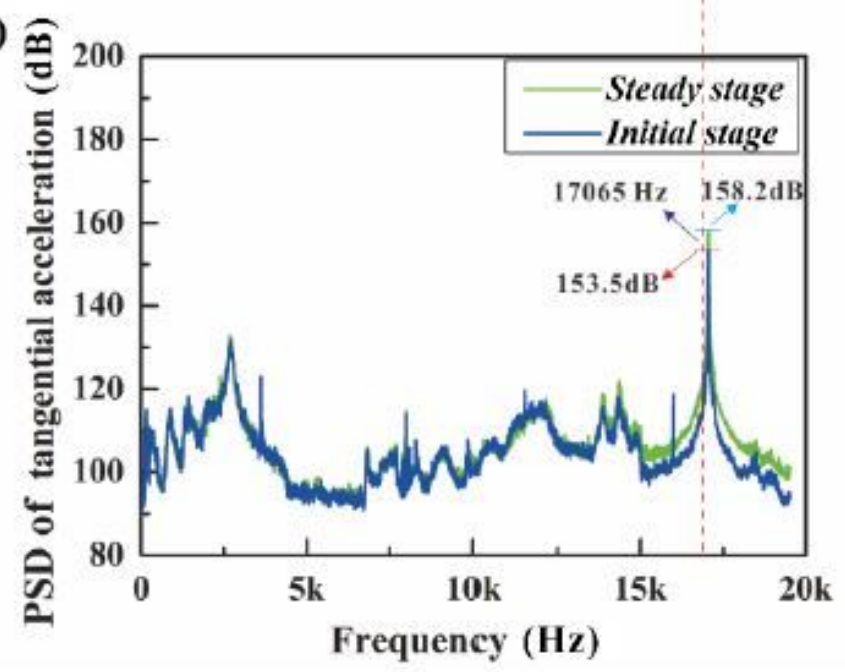

Figure 15

PSD comparison of vibration noise and vibration acceleration signals of two systems at two phases 


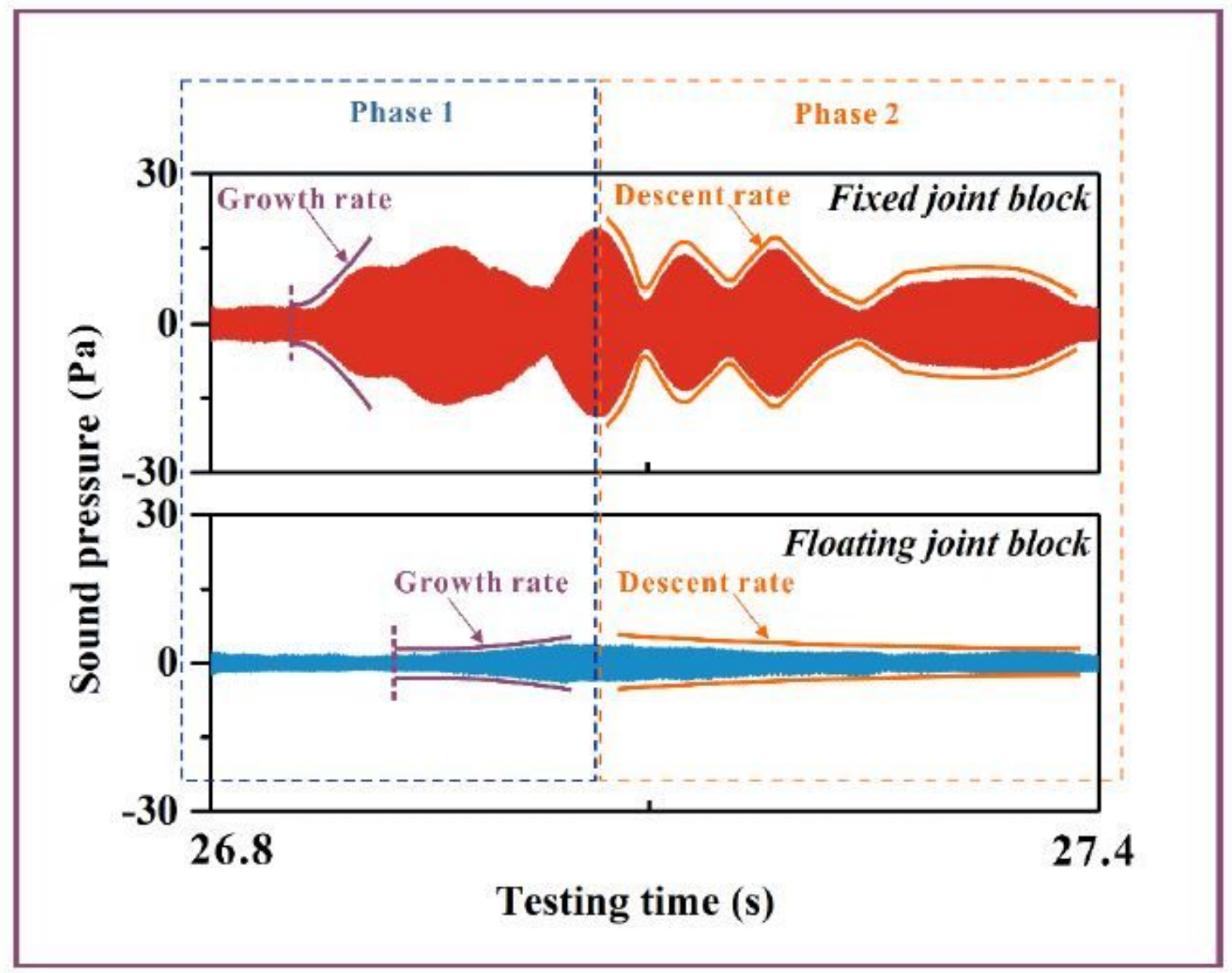

Figure 16

Comparison of one-cycle vibration noise from two systems during the stable phase 


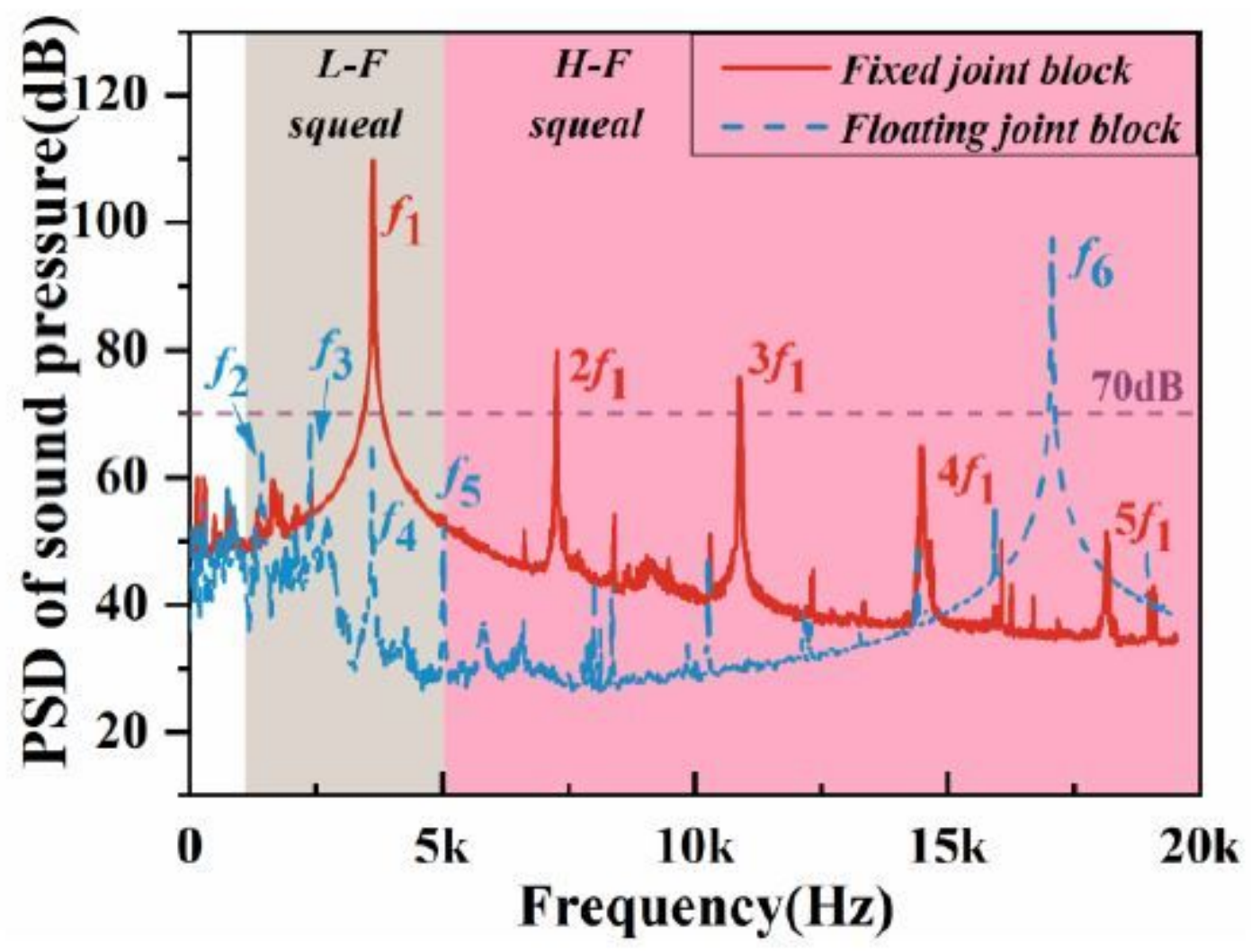

Figure 17

Comparison of vibration noise analysis in frequency domain during the stable phase of two systems 


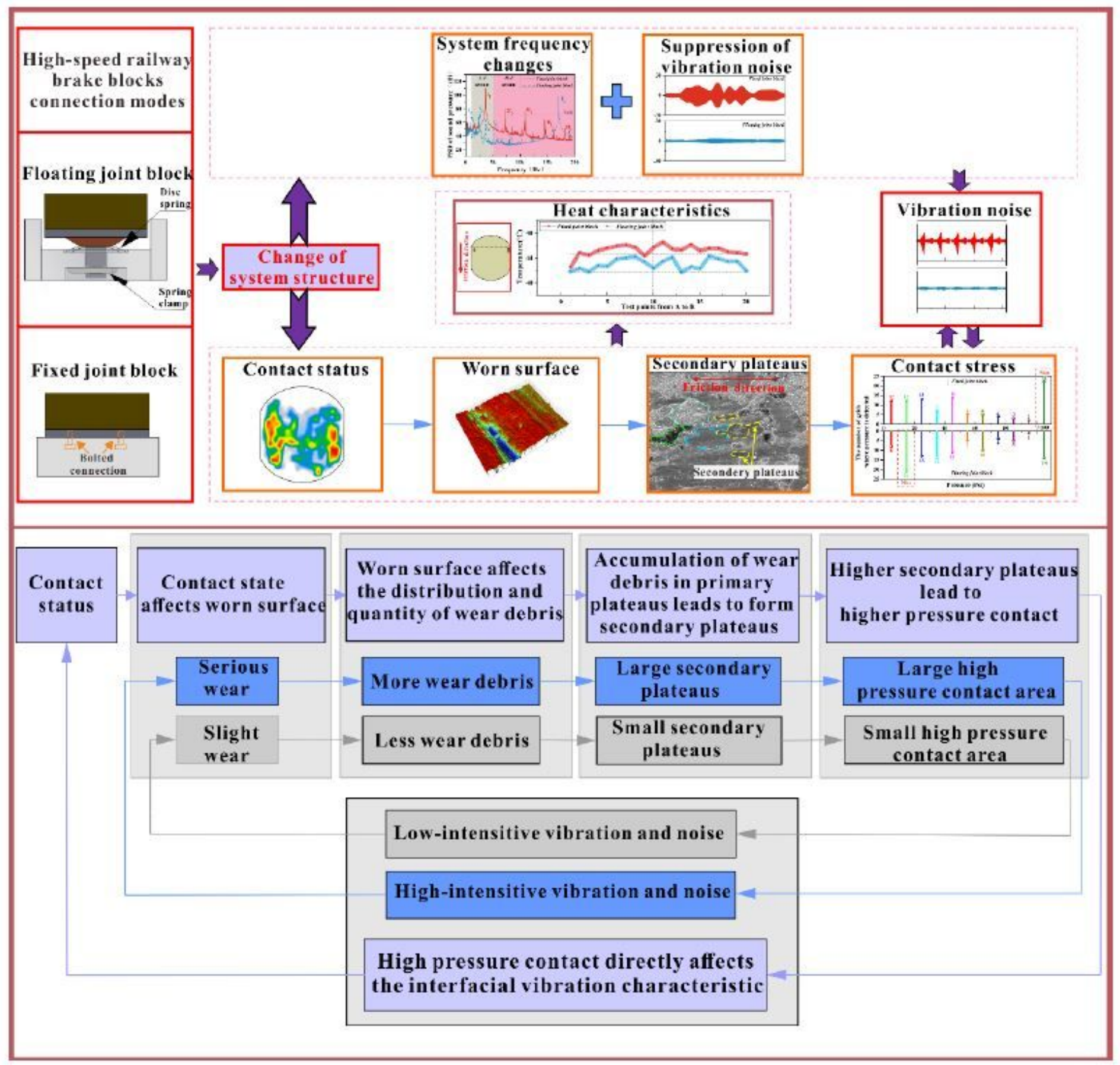

Figure 18

Schematic diagram of the relationship between connection modes of friction blocks and systematic performance (interface characteristics, heat distribution and vibration noise behavior) 